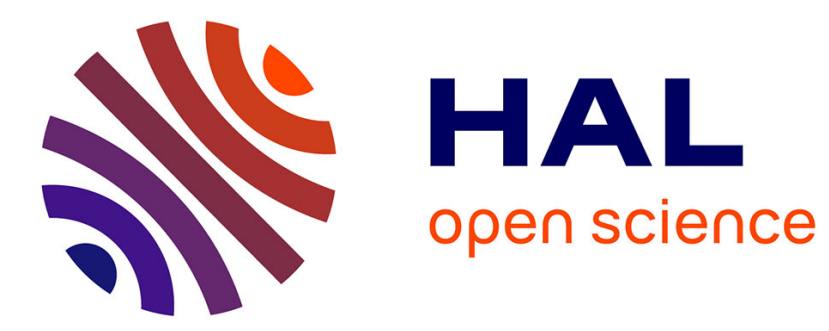

\title{
Spontaneous narrative behaviour in homo sapiens: how does it benefit to speakers?
}

Jean-Louis Dessalles

\section{To cite this version:}

Jean-Louis Dessalles. Spontaneous narrative behaviour in homo sapiens: how does it benefit to speakers?. The evolution of language - Proceedings of the 7th International Conference (Evolang7 Barcelona), 2008, Singapore, Spain. pp.91-98. hal-00614789

\section{HAL Id: hal-00614789 \\ https://hal.science/hal-00614789}

Submitted on 22 Aug 2011

HAL is a multi-disciplinary open access archive for the deposit and dissemination of scientific research documents, whether they are published or not. The documents may come from teaching and research institutions in France or abroad, or from public or private research centers.
L'archive ouverte pluridisciplinaire HAL, est destinée au dépôt et à la diffusion de documents scientifiques de niveau recherche, publiés ou non, émanant des établissements d'enseignement et de recherche français ou étrangers, des laboratoires publics ou privés. 
Dessalles, J-L. (2008). Spontaneous narrative behaviour in homo sapiens: how does it benefit to speakers?. In A. D. M. Smith, K. Smith \& R. Ferrer i Cancho (Eds.), The evolution of language - Proceedings of the 7th International Conference (Evolang7 - Barcelona), 91-98. Singapore: World Scientific. http://www.enst.fr/ jld/papiers/pap.evol/Dessalles_07091501.pdf

\title{
SPONTANEOUS NARRATIVE BEHAVIOUR IN HOMO SAPIENS: HOW DOES IT BENEFIT TO SPEAKERS?
}

\author{
JEAN-LOUIS DESSALLES \\ ENST, ParisTech, 46 rue Barrault \\ Paris, F-75013, France
}

\begin{abstract}
The fact that human beings universally put much energy and conviction in reporting events in daily conversations demands an explanation. After having observed that the selection of reportable events is based on unexpectedness and emotion, we make a few suggestions to show how the existence of narrative behaviour can be consistent with the socio-political theory of the origin of language.
\end{abstract}

\section{Spontaneous narratives: a fundamental component of language}

Dozens of times everyday, human individuals feel the urge to signal current events or to report past events to their conspecifics. In doing so, they respond to specific stimuli such as departure from norm, coincidences or emotion. This event reporting behaviour seems to be unique in nature (Boyd 2001), as remote analogues such as bee dance and alarm calls do not compare with it. During conversational narratives, the speaker may hold the floor during several minutes, with no other interruption than minimal approval signals emitted by interlocutors. Within a Darwinian framework, the existence of such behaviour requires an explanation. How does this time-consuming activity, which deals most often with futile anecdotes that are unlikely to be of any direct interest for survival, benefit not only to listeners, but also to speakers?

We first show the importance of narratives by providing quantitative estimates. Then we outline a cognitive characterization showing that individuals respond to definite stimuli when selecting reportable events. Lastly, we look for plausible Darwinian explanations for the existence of narrative behaviour, in line with our socio-political account of the origins of language.

\section{Narratives in daily speech}

Human beings make extensive use of their language ability. Individuals have been observed to speak 15000 words a day on average (Mehl et al. 2007). This 
behaviour covers several activities which can be distinguished by the cognitive mechanisms involved. The two main components of spontaneous language use are discussion (argumentation) and narration (event reporting) (Dessalles 2007a). The proportion of event reporting may vary significantly from one corpus to the next. Suzanne Eggins and Diana Slade (1997) observed the repartition indicated in Table 1 in the three hours of casual conversation data they collected during coffee breaks in three different workplaces. Storytelling takes up the major share in this distribution.

Table 1: Distribution of conversational topic types in Eggins and Slade's corpus (1997 p. 265)

\begin{tabular}{ll}
\hline Conversation type & $\%$ \\
\hline Storytelling & 43.4 \\
Observation/Comment & 19.75 \\
Opinion & 16.8 \\
Gossip & 13.8 \\
Joke-telling & 6.3 \\
\hline
\end{tabular}

We made similar measures on our main corpus, composed of 17 hours of conversations, recorded during meals at family gatherings between 1978 and 1988 among educated individuals belonging to a French middle class family. The distribution of conversation types was explored through a sampling method (Figure 1). The corpus has been digitalized, and 150 excerpts of $120 \mathrm{~s}$. have been automatically extracted at random positions. For each excerpt, the central utterance (occurring at time $60 \mathrm{~s}$.) has been assigned a category (Table 2).

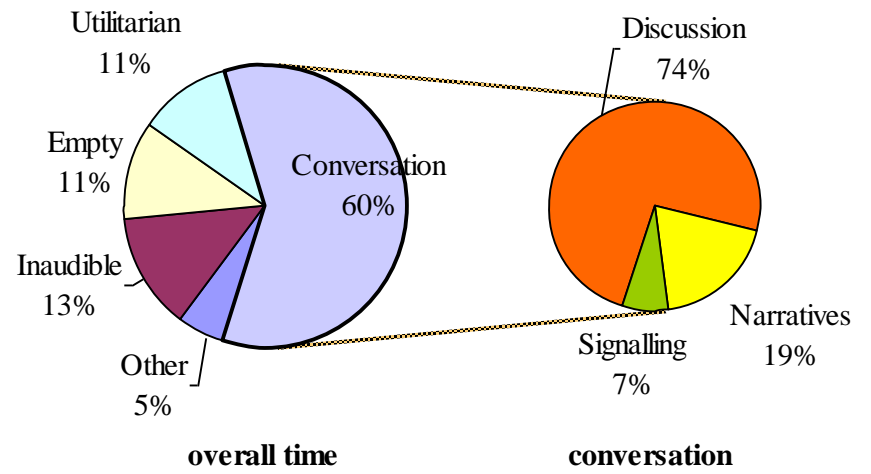

Figure 1. Distribution of utterance types in our own corpus, assessed through a sampling method. 
The small relative size of the 'empty' category reveals that in this family meal context, language is used $89 \%$ of the time. Conversation proper, which excludes utilitarian (more or less ritualized) speech, occupies nearly $70 \%$ of the time (as most of inaudible utterances are likely to be conversational). Narratives and signalling together amount to $26 \%$ of conversation time. Though it is less than in Eggins and Slade's corpus, event reporting still represents a significant share of spontaneous language use. Quantitative data about conversational narratives are unfortunately lacking, especially for intercultural comparisons. We can only conjecture that no culture lacks spontaneous narrative behaviour, as such a people would have been well-known for its conversational specificity.

Table 2: Definition of utterance types in the family conversation corpus

\begin{tabular}{|c|c|c|}
\hline Utterance type & Definition & Example \\
\hline Narratives & $\begin{array}{l}\text { Reports about past situated } \\
\text { events }\end{array}$ & $\begin{array}{l}\text { Dishwasher breakdown which turned out } \\
\text { to be a mere leak from a plastic bottle }\end{array}$ \\
\hline Signalling & $\begin{array}{l}\text { Drawing attention to current } \\
\text { facts }\end{array}$ & $\begin{array}{l}\text { Showing a new electronic personal } \\
\text { organizer }\end{array}$ \\
\hline Discussion & Dealing with problems & Who's going to be the next Prime Minister \\
\hline $\begin{array}{l}\text { Utilitarian } \\
\text { speech }\end{array}$ & $\begin{array}{l}\text { Offers, requests,... (mostly in } \\
\text { relation with food) }\end{array}$ & Offering more foie gras \\
\hline Other & Songs, child screaming & Singing to bring a child to sing along \\
\hline Inaudible & $\begin{array}{l}\text { Superimposed noise, } \\
\text { simultaneous conversations }\end{array}$ & \\
\hline Empty & $\begin{array}{l}\text { No speech, no utterance in } \\
\text { progress }\end{array}$ & \\
\hline
\end{tabular}

Narrative speech contrasts with the other main discourse category, discussion. Superficially, the most manifest difference is that narratives deal with situated events, whereas discussion deals with problems and their solutions. When facts are mentioned during a discussion, they are most often not situated (e.g. 'Fabius [a potential Prime Minister] makes a better impression on TV'), though there are cases in which situated facts or genuine stories are recounted in support of an argument (two occurrences in the sample). But narration and discussion can be opposed more fundamentally on the cognitive ground. Discussion consists in settling an issue or solving an epistemic puzzle. It proceeds through a characteristic problem-abduction-revision procedure (Dessalles 2007a). By contrast, event reporting relies on unexpectedness and emotion elicitation (see below). Though narrative and argumentative moves may 
be intertwined in conversation, they often remain separate: arguments spark off arguments in a typical problem-solution alternation, whereas narratives spark off new narratives, generating 'story rounds' (Tannen 1984 p. 100).

Events reported in conversations are most often not fictional (only one example in the sample can be considered fictitious, as it consists in describing the content of a cartoon). Though fiction seems to obey definite patterns (Hogan 2003), conversational narratives seem to be ruled by even more constraining imperatives. Any narrative must have an interesting point (Labov 1997), as otherwise speakers may be regarded as socially inept (Polanyi 1979 p. 211). In what follows, we propose a cognitive characterization of competent storytelling, before considering its possible biological role.

\section{The selection of reportable events}

The dozens of episodes that human beings tell each day through conversational narratives represent only a tiny fraction of their actual experience. The selection of reportable events (Labov 1997) obeys specific patterns. In what follows, we highlight two fundamental requirements that are deeply rooted in our cognition: reportable events must be unexpected and/or arouse emotion.

\subsection{Unexpectedness}

The property of unexpectedness covers various aspects of newsworthiness, including deviance, atypicality, rarity, proximity, remarkable structures, and coincidences. In former accounts, we equated unexpectedness with improbability (Dessalles 2002). Though, the model left important cases unexplained. Individuals consider situations that depart from the norm for some qualitative reason (e.g. jogging nuns) highly unexpected, what probability theory fails to explain. Our new model (Dessalles 2007b), based on formal complexity (Li \& Vitányi 1993), makes correct predictions for all situations perceived as unexpected. We found that the relevant parameter is the contrast between the expected and the actual complexity of the situation. While a standard encounter with nuns is expected to be complex to individuate, encountering jogging nuns is maximally simple, thanks to their unique characteristics. Similarly, a narratable fortuitous encounter is all the more unexpected since the person one bumped into is simple (a close friend or a celebrity) and the place is remote enough to be complex. Complexity contrasts turn out to have a systematic influence on reportability (Dessalles 2007b).

Assessing variations of individuation complexity is certainly not a trivial cognitive operation, but every human being seems to be equipped to perform it. 
The universal sensitivity to unexpectedness is a fundamental component of narrative competence and must have been selected for definite reasons.

\subsection{Emotion}

Emotion is the other parameter that stimulates event reporting. Emotional situations are systematically shared (Rimé 2005). In the following conversation from Neal Norrick's corpus (2000 p. 64), a young man recalls an accident story his aunt told him (transcription details omitted).

Mark: you know what happened to my one of my aunt's friends out in Iowa? Like when-when she was younger, she had a headgear from braces, and these two girls were wrestling around just playing around, wrestling. And one girl pulled her headgear off her mouth and let it snap back. And it slid up her face and stuck in her eyes and blinded her.

Jacob: wow.

Mark: isn't that horrid? That's horrid. Blinded her for life. Isn't that horrid. That's just-I mean just from goofing around.

Unexpectedness and emotion are often combined to enhance reportability. Unexpectedness here lies in the contrast between standard play situations, which are complex to individuate because they are all alike, and the actual situation which is unique by its consequences. Mark's final remark points to this contrast.

Studies show that emotion is reactivated during recounts, and this can be seen as a paradox (Rimé 2005 p. 109). Quite surprisingly, bringing back memories about negative emotions and sharing them with listeners is experienced as enjoyable by both parties. People like to talk not only about positive events, but also about events that generated fear, sadness, anger, guilt, embarrassment, contempt and even shame. They also like to listen to others' corresponding experiences, despite the fact that the evocation of such events produces negative feelings similar to the original ones. It seems that the pleasure of sharing these feelings compensates for experiencing them again.

\section{Why are conversational stories told?}

The pervasive presence of stories in conversations is an embarrassment for most accounts of the evolutionary origin of language. If language has been selected because of its effect on the welfare of the group (Victorri 2002; Castro et al. 2004 p. 734; Ritt 2004 p. 1-2) or as a fair exchange of information based on strict reciprocity (Pinker 2003 p. 28; Nowak 2006 p. 1561), then the efforts that speakers devote to tell stories for all to hear, most often with much emphasis to 
highlight interest, is incomprehensible. We would expect speakers to whisper minimal factual information to specific ears and then demand of listeners that they reciprocate. What may be true for crucial advice (such as which shares to buy on the stock exchange) does not apply to conversational stories.

Other accounts emphasize the educational value of language (Fitch 2004; Castro et al. 2004 p. 725). But stories are found to be spontaneously told, not only from adults to children, but also from adults to adults and even from children to adults. As soon as by nine months of age, children spontaneously point to unexpected stimuli (Carpenter et al. 1998). More generally, theories of language function that emphasize the practical value of information are at odds with the fact that most stories are about futile matters. Unexpected events are, by essence, unlikely to occur again. Any practical processing of information would concentrate on vital information (danger, food, mating opportunities) and would neglect the myriad of anecdotal facts that fill daily chatter. Animals do not care about situations just because they are unexpected: they show no interest four-leaf clovers, they would regard a unicorn as a mere horse and they do not care about coincidences. Human communication, on the other hand, is universally replete with details about inconsequential episodes, just because of their unexpectedness, and this requires an evolutionary explanation.

The key difference seems to lie in human sociality: we crave the attention of others and narratives are a major way to do so (Boyd 2001). This makes sense within our political theory of the origin of language (Dessalles 2007a), which states that individuals use language to demonstrate qualities that are in demand in the establishment of solidarity bonds. To fit in with the model, however, the qualities shown when telling stories must have political significance. In what way does the ability to produce unexpectedness and elicit emotions correlate with being a valuable coalition partner?

Though these issues have not been properly investigated yet, we may have some idea. First, from early age on, individuals are in competition to demonstrate that they knew first, as in the next exchange, observed between two children aged eight and ten:

M: Did you see there are more [hot-air] balloons up there this morning?

Q: Yes, I know.

M: You, be quiet! I'm not talking to you, I'm talking to the others. [To his father] Did you see there are balloons up there this morning?

Being the first who noticed the presence of balloons is important for $\mathrm{M}$, as his second utterance shows. The first-to-know phenomenon is the most obvious case in which unexpectedness is produced. Reclaiming authorship for the news is 
understandable if, as we suggest, language is display (Dessalles 2007a). The informational competence that individuals display by offering scoop stories to conspecifics reveals crucial in the specific political context of our species.

Hominins are 'apes with spears'. ${ }^{1}$ The introduction of deadly weapons in an ape species dramatically changes the political game: physical strength becomes much less relevant. The best strategy to survive is to share one's fate with other individuals (here, we radically depart from Paul Bingham's (2001) theory, in which the main effect of weapons is to enforce cooperation through retaliation within coalitions). In a context in which every individual must choose allies, the problem is to determine the best ones. Those who are able to spot unusual goings-on are a good choice, as they are the first to warn for complex danger. Since that time, individuals crave for displaying their ability to notice unexpectedness, as they are descended from ancestors for whom it was a good way to be accepted as coalition partners. Still now, individuals who are able to bring unexpected news are perceived as 'interesting' and are preferentially chosen as friends. They get social success, whereas boring individuals are avoided. Of course, the political game is more complex in our species than in the first hominin species. However, those who are able to spot unexpected situations or activities remains a crucial asset in a species in which being taken by surprise may be fatal. The claim is thus that there is continuity in the signalling and narrative behaviour along the hominin lineage down to sapiens, as it remains a way for individuals to show off their value as coalition partner.

Why do individuals tell emotional narratives? Emotions displayed in stories are associated with political values, such as solidarity or courage. By showing that they are able to experience compassion, pity, concern, indignation at cowardice, cheating or unfairness, that they admire selfless love and feats, individuals try to appear as ideal friends. If we accept that successfully communicated emotions are hard to fake, then expressing them through stories is a reliable indication that one really values the corresponding qualities.

Human beings are information oriented animals, who exchange stories on a daily basis. We tried to indicate how this fact, which is hard to explain in traditional accounts of language origins, can be a natural outcome of the particular socio-political organization of our species, in which individuals must compete by demonstrating their information qualities in order to attract friends.

\footnotetext{
${ }^{1}$ Spears may be thought to have been the first efficient weapons used by hominins: they are easy to make and to carry (the use of spears may have contributed to make biped walk advantageous).
} 


\section{References}

Bingham, P. M. (2001). Human evolution and human history: A complete theory. Evolutionary anthropology, 9 (6), 248-257.

Boyd, B. (2001). The origin of stories: Horton hears a who. Philosophy and Literature, 25 (2), 197-214.

Carpenter, M., Nagell, K. \& Tomasello, M. (1998). Social cognition, joint attention, and communicative competence from 9 to 15 months of age. Monographs of the Society for Research in Child Devel., 255(63), 1-143.

Castro, L., Medina, A. \& Toro, M. A. (2004). Hominid cultural transmission and the evolution of language. Biology and philosophy, 19, 721-737.

Dessalles, J-L. (2002). La fonction shannonienne du langage : un indice de son évolution. Langages, 146, 101-111.

Dessalles, J-L. (2007a). Why we talk - The evolutionary origins of language. Oxford: Oxford University Press. http://www.enst.fr/ jld/WWT/

Dessalles, J-L. (2007b). Complexité cognitive appliquée à la modélisation de l'intérêt narratif. Intellectica, 45.

Eggins, S. \& Slade, D. (1997). Analysing casual conversation. London: Equinox.

Fitch, W. T. (2004). Evolving honest communication systems: Kin selection and 'mother tongues'. In D. K. Oller \& U. Griebel (Eds.), The evolution of communication systems, 275-296. Cambridge, MA: MIT Press.

Hogan, P. C. (2003). The mind and its stories - Narrative universals and human emotion. Cambridge, UK: Cambridge University Press.

Li, M. \& Vitányi, P. (1993). An introduction to Kolmogorov complexity and its applications. New York: Springer Verlag, ed. 1997.

Mehl, M. R., Vazire, S., Ramírez-Esparza, N., Slatcher, R. B. \& Pennebaker, J. W. (2007). Are women really more talkative than men?. Science, 317, 82.

Norrick, N. R. (2000). Conversational narrative: storytelling in everyday talk. Amsterdam: John Benjamins Publishing Company.

Nowak, M. A. (2006). Five rules for the evolution of cooperation. Science, 314, 1560-1563.

Pinker, S. (2003). Language as an adaptation to the cognitive niche. In M. H. Christiansen \& S. Kirby (Eds.), Language Evolution, 16-37. Oxford: Oxford University Press.

Polanyi, L. (1979). So What's the point?. Semiotica, 25 (3), 207-241.

Rimé, B. (2005). Le partage social des émotions. Paris: PUF.

Ritt, N. (2004). Selfish sounds and linguistic evolution - A Darwinian approach to language change. Cambridge: Cambridge University Press.

Tannen, D. (1984). Conversational style - Analyzing talk among friends. Norwood: Ablex Publishing Corporation.

Victorri, B. (2002). Homo narrans : le rôle de la narration dans l'émergence du langage. Langages, 146, 112-125. 
